Nigerian Journal of Physiological Sciences 24 (2): 101 - 106 @Physiological Society of Nigeria, 2009

Available online/abstracted at http://www.bioline.org.br/np; www.ajol.info/journals.njps; www.cas.org

\title{
COMPARATIVE STUDY OF ARTESUNATE, ACTS AND THEIR COMBINANTS ON THE HORMONAL PARAMETERS OF THE MALE GUINEA-PIG
}

A. W. OBIANIME AND J. S. APRIOKU*

Department of Pharmacology, Faculty of Basic Medical Sciences, University of Port Harcourt, Choba, Rivers State, P.M.B. 5323, Nigeria. E-mail: sydaprio@yahoo.com Tel: +2348035082379

Summary: In this study, the effects of half, normal and double clinical doses of artesunate; artesunate/sulfadoxine/ pyrimethamine; artesunate/amodiaquine and their combinants (sulfadoxine/pyrimethamine and amodiaquine) on the basal serum levels of testosterone, FSH, LH and prolactin of the guinea-pig were investigated. The results of this study showed that the agents caused significant decreases $(\mathrm{p}<0.05)$ in serum testosterone level, with varying effects on LH, FSH and prolactin. Testosterone level was decreased by artesunate (37\%), sulfadoxine/pyrimethamine (22\%), amodiaquine (14\%), artesunate/sulfadoxine/pyrimethamine (41\%) and artesunate/amodiaquine (49\%) at the clinical dose, compared to the serum levels in control animals. Furthermore, artesunate and amodiaquine also caused moderate decreases in the serum concentrations of LH and FSH, without an effect on prolactin. The effects of these agents may be due to oxidative stress on the reproductive system of the organism.

Keywords: Testosterone, ACTs, artesunate, hormones and Guinea pig

\section{Introduction}

Malaria is a worldwide public health problem, with enormous health and economic consequences (WHO, 1998; Aultman et al., 2002; Sachs and Malaney, 2002). The disease is caused by different species of the genus Plasmodium (including $P$. falciparium, $P$. vivax, $P$. ovale, and $P$. malariae).

The treatment of malaria has faced several challenges due to the development of resistance of the parasite (White, 1999; Wellems and Plowe, 2001; Yeung et al., 2004), cost and adverse effects of antimalarial agents (Bloland et al., 2000). Different classes of drugs have been developed and used for the treatment of the disease. In the past, the inexpensive and orally administered antimalarial drug, chloroquine, was the "gold standard" treatment. Unfortunately development of resistance to certain plasmodium strains has made chloroquine ineffective and almost useless for malaria treatment in some areas (Kofi, 1983; Djimdé et al., 2001). The present drugs of choice are the artemisinin and its derivatives which have been reported to be highly efficacious with minimal toxicity (Mulenga, 1998; Haynes, 2001). Furthermore, studies have shown that monotherapy with the artemisinins has resulted in some levels of treatment failures (Price et al., 1998; McIntosh and Olliaro, 2000) and that drug combinations markedly delay the emergence of resistance (Curtis and Otoo, 1986; Chawira et al., 1987). This has therefore necessitated the use of combined therapy of artemisinin with other antimalarial agents known as the artemisinin-based combination treatments (ACTs). These combinations include- artesunate-sulfadoxine-pyrimethamine (SP), artesunate-amodiaquine, artemether-lumefantrine and artesunate-mefloquine as recommended by WHO. The ACTs are particularly effective because of their high killing rates through their schizonticidal and asexual killing potentials. This potential had made them to become the main chemotherapeutic agents for malaria treatment (WHO, 1995; White, 1999; Nosten and White, 2007).

However, the prevalence of malaria has resulted in indiscriminate use, abuse and patients noncompliance to therapeutic regimens, which could result in clinical toxicity of these agents. Furthermore, most scientific studies on artemisinins recorded are on the effects of artemisinin and its derivatives alone (monotherapy) without a correlative study of the combinant agents in the ACT therapy (Raji et al., 2005; Nwanjo et al., 2007). Finally, all former studies carried out were with mice and albino rats, without any investigations on the effects of the above on guinea-pigs. It is therefore in that light that we had carried out a toxicological correlative study of the effects of the artemisinin derivatives (artesunate), the combinant drugs (amodiaquine and sulfadoxine/pyrimethamine) and their combined therapies (ACTs) on male guinea-pigs. In summary, the question asked was since combine therapy (ACT) will result in faster and better killing of the malaria parasite and remission (White, 1999), will the therapy also result in lower or enhanced toxicity?

\section{Materials and methods}

Drugs

All the drugs used were obtained from the University of Port Harcourt Teaching Hospital (UPTH), Port Harcourt. The artemisinin derivative 
A. W. OBIANIME and J. S. APRIOKU

used was artesunate (Arinate), manufactured by ERFA, Rue des Cultivateurs 25, 1040 Brussels. The ACTs were- artesunate/sulphadoxine/ pyrimethamine (Farenax) and artesunate/amodiaquine (Dart) manufactured by Swiss Pharma Nigeria Ltd, Lagos, Nigeria; while the combinant drugs were amodiaquine (Camoquine) manufactured by Pfizer Afrique de I'Quest BP 3857 - Dakar R.P. Senegal and sulfadoxine/pyrimethamine (Fansidar) by Swiss Pharma Nigeria Ltd, Lagos, Nigeria. The agents were administered in distilled water obtained from the Department of Chemistry, Faculty of Sciences, University of Port Harcourt, Nigeria.

\section{Animals}

Outbred strains of adult male guinea-pigs (GPs) of average weight $450 \pm 5 \mathrm{~g}$ were obtained from the animal house of the University of Port Harcourt, Nigeria and allowed to acclimatize for 14 days. The guinea-pigs were fed with alfalfa feeds and water daily ad libitum at a room temperature of $29 \pm 2^{\circ} \mathrm{C}$ with 12-h light/dark cycle.

\section{The effects on testicular hormonal parameters}

The animals were divided into six (6) groups- A, B, C, D, E and F of five animals each and orally administered with the following normal clinical doses of the agents.

The animals in group A was given $2 \mathrm{mg} / \mathrm{kg}$ body weight of artesunate 12-hourly for three days. Animals in group B were given $10 \mathrm{mg}$ base $/ \mathrm{kg}$ body weight of amodiaquine once daily for three days, while those in group $\mathrm{C}$ received a single dose of $1.25 / 25 \mathrm{mg}$ base $/ \mathrm{kg}$ body weight of sulfadoxine/pyrimethamine. The animals in group D were given $4 \mathrm{mg} / \mathrm{kg}$ body weight of artesunate and $10 \mathrm{mg}$ base $/ \mathrm{kg}$ body weight of amodiaquine once a day for 3 days. The animals in group $E$ (which served as the control were given only distilled water once daily for three days.

These experiments with the antimalarial agents were carried out simultaneously with other sets of animals using half and double the normal clinical doses of the antimalarial agents. At the end of each treatment course, the animals were sacrificed and blood samples were collected by cardiac puncture and assayed for FSH, LH, prolactin and testosterone using enzyme linked immunoassay (EIA) technique.

\section{Statistical analysis}

Data were expressed as means \pm standard errors of mean. Comparisons between control and treated groups of guinea-pigs were performed with one-way analysis of variance (ANOVA), followed by Duncan's multiple comparison test. Statistical significance was set at $\mathrm{P}<0.05$.

\section{Results}

In $\mathrm{n}=5$, artesunate, ACTs and their combinants used in this experiment caused significant $(\mathrm{p}<0.05)$ decreases in the serum concentrations of testosterone, with varying effects on $\mathrm{LH}, \mathrm{FSH}$ and prolactin. These effects were non-dose-dependent and generally most pronounced at the lower doses (subclinical and clinical doses), with the combination products (ACTs) causing non synergistic but more damaging inhibitory effects (Figs. 1a and b). The serum values obtained at the normal clinical dose with artesunate, sulfadoxine/pyrimethamine and amodiaquine were $1.98 \pm 0.29,2.45 \pm 0.41$ and $2.7 \pm 0.27 \mathrm{ng} / \mathrm{ml}$, which when compared to the basal serum level of $3.14 \pm 0.24$ $\mathrm{ng} / \mathrm{ml}$ represented 37, 22 and $14 \%$ decreases respectively. These values were also very significant at $\mathrm{p}<0.05$. However, the values for the ACTsartesunate/ sulfadoxine/pyrimethamine and artesunate /amodiaquine were $1.85 \pm 0.87$ and $1.60 \pm 0.29$ (41 and $49 \%$ decreases) respectively, which showed potentiation of the effects of the individual agents (Figs. 1a, b and c).

Artesunate and amodiaquine caused moderate decreases in the basal serum concentrations of $\mathrm{LH}$ and FSH, while the other agents had little or no effect on serum LH level (Figs. 2 and 3). The effects of artesunate on LH were significant $(\mathrm{p}<0.05)$ at all doses and most pronounced at the lower doses- half and normal clinical doses (Figs. 2a and b). The serum values obtained were $2.88 \pm 0.05$ and $2.09 \pm 0.09 \mathrm{~g} / \mathrm{L}$, compared to the control serum value of $3.45 \pm 0.10$ g/L (Figs. 2a and b).

Furthermore, the effects of artesunate and amodiaquine on FSH were significant $(\mathrm{p}<0.05)$ at the subclinical dose, decreasing basal serum FSH level from $2.44 \pm 0.09$ to $2.03 \pm 0.09$ and $2.05 \pm 0.06 \mathrm{~g} / \mathrm{L}$ respectively (Figs. 3a and b). Finally, half clinical doses of artesunate and sulfadoxine/pyrimethamine caused significant decreases in serum prolactin levels in treated animals, compared to the control animals, while the other agents caused no significant changes in prolactin levels (Figs. 4a and b). 
Artesunate, ACTs and their combinants on the hormonal parameters
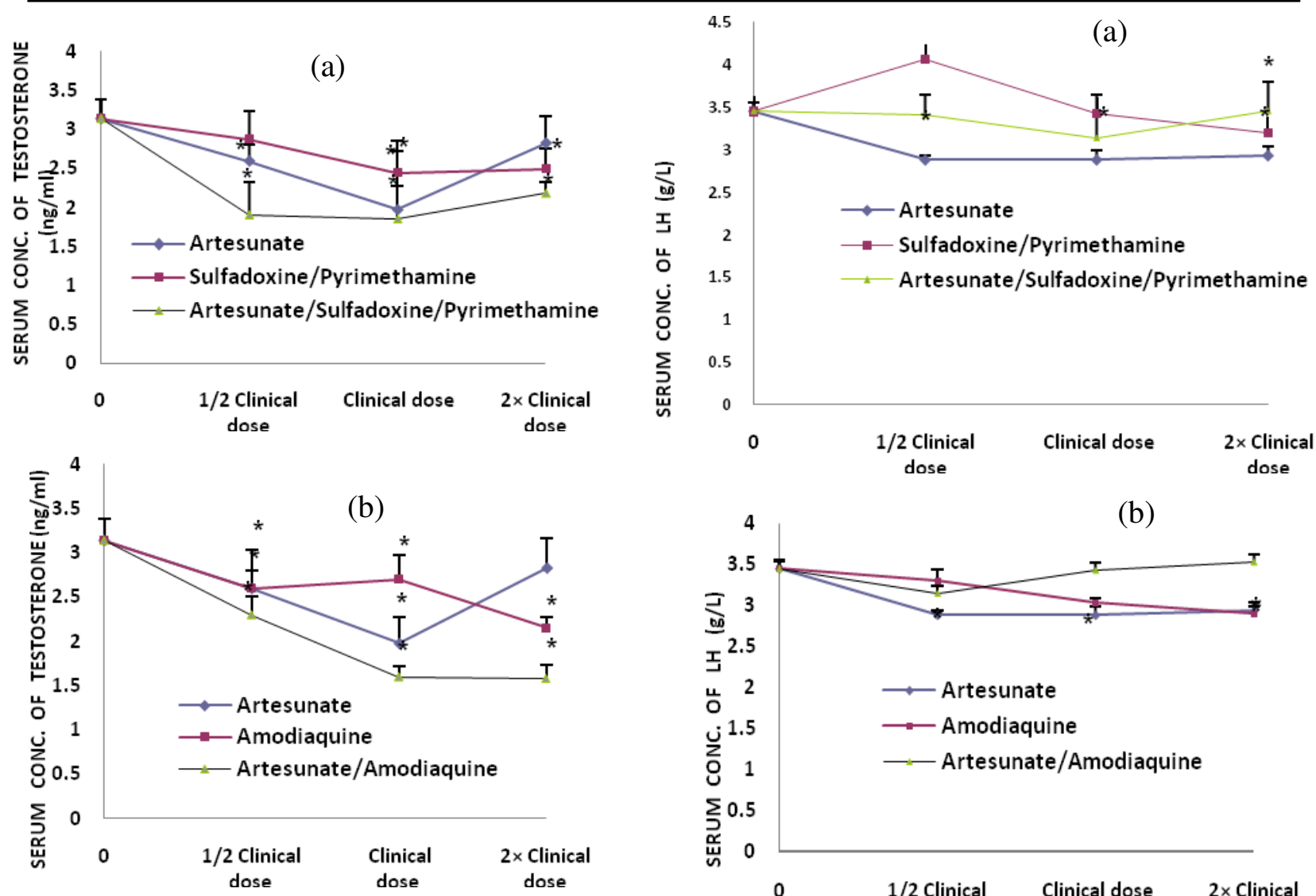

Fig. 1: The effects of antimalarial agents on serum testosterone levels of male GPs. Data are mean \pm SEM, $n=5$; *Significantly different from control at $p<0.05$ ANOVA.

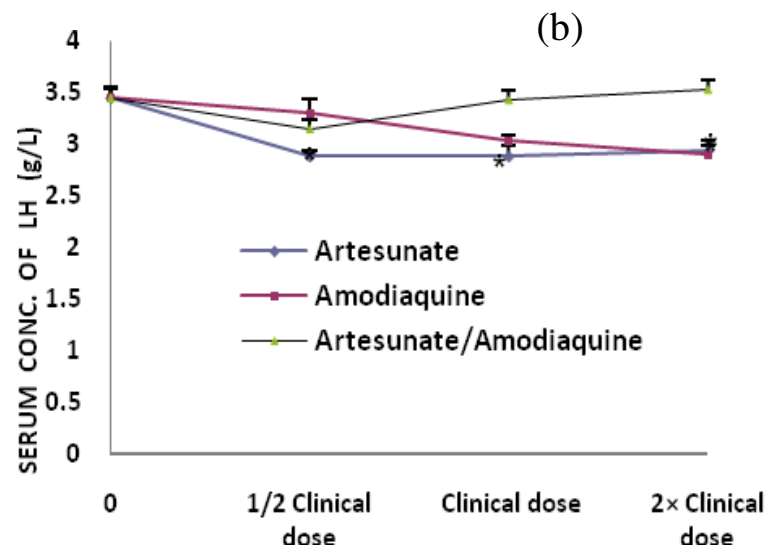

Fig. 2: The effects of antimalarial agents on serum Leutinizing Hormone (LH) levels of male GPs. Data are mean \pm SEM, $n=5$; $*$ Significantly different from control at $\mathrm{p}<0.05$ ANOVA.
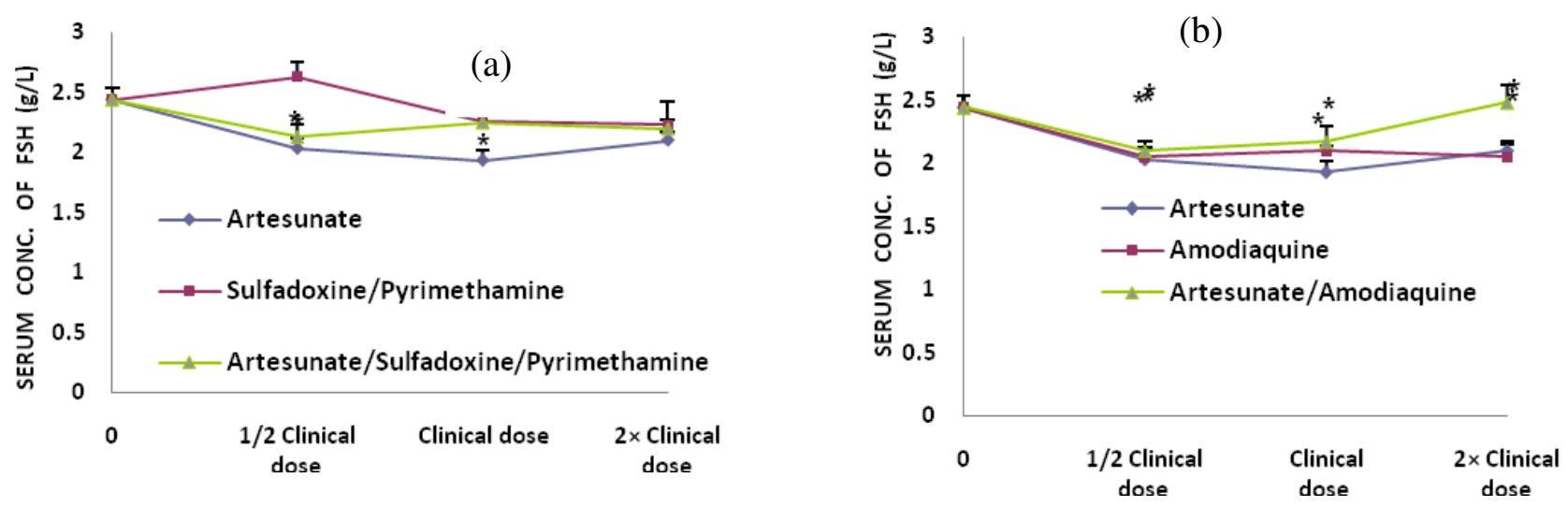

Fig. 3: The effects of antimalarial agents on the serum Follicle Stimulating Hormone (FSH) levels of male GPs. Data are mean $\pm S E M, n=5 ; *$ significantly different from control at $p<0.05$ ANOVA. 

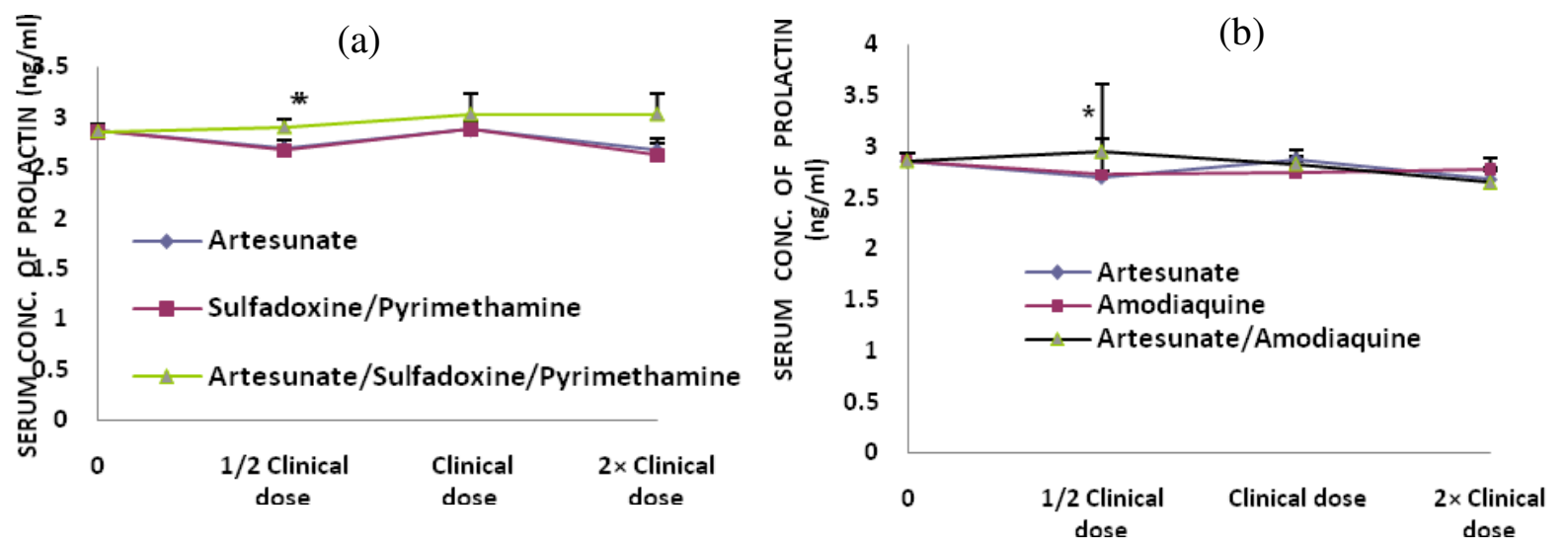

Fig. 4: The effects of antimalarial agents on serum Prolactin levesl of male GPs. Data are mean $\pm S E M, n=5 ; *$ significantly different from control at $p<0.05$ ANOVA.

\section{Discussion}

Most antimalarial agents had been shown to be toxic to male gonadal functions (Sairam, 1978; Adeeko and Dada, 1998; Orisakwe, et al, 2003; Raji et al, 2005). Furthermore, previous studies on the effects of artemisinins in male reproductive dysfunction had been centered on single artemisinin agents, using mice and albino rats (Raji et al, 2005; Nwanjo et al, 2007). In respect of specie variation as it concerns drug metabolism, the present study investigated the comparative effects of artesunate (as a single agent), ACTs and the partner antimalarial agents (combinants) on some male reproductive hormones in the male guinea-pig. The study was intended to evaluate or assess the therapeutic indices of the "wonder" antimalarial regimens (ACTs) against single artemisinin derivatives and the combinants.

In this study, artesunate decreased serum LH levels at all doses, amodiaquine at the double clinical dose, while sulfadoxine/pyrimethamine caused an increase at subclinical dose, without significant effects at the other doses. The other agents had no significant effects. Furthermore, artesunate and amodiaquine significantly decreased serum FSH, while artesunate/amodiaquine and artesunate/ sulfadoxine/pyrimethamine caused no significant effects. These results indicate that artesunate combinations with amodiaquine and sulfadoxine/ pyrimethamine caused moderation of the effects of the individual agents on LH and FSH. The agents also had no significant effects on prolactin activity.

Furthermore, all the agents caused significant decreases in serum testosterone levels mostly at the subclinical and clinical doses of the drugs. Artesunate caused significant decrease in serum testosterone level, which is consistent with the findings of a similar study with artemether (Raji et al, 2005). In addition, sulfadoxine/ pyrimethamine, amodiaquine and halofantrine also caused significant decreases in serum testosterone level, which is also consistent with the observations of (Orisakwe et al, 2003). However, the ACTs caused greater effects compared to the individual agents.

Nosten and White, (2007) had reported that artemisinin and its derivatives on their own are relatively free from toxicological effects and that any toxicity observed in artemisinin combination treatments may be due to the partner agent. This is inconsistent with the results of the present study, where the ACTs and their combinants caused very significant inhibition of testosterone activity, which could result in impaired testicular and reproductive function..

Testicular function is influenced and regulated by testicular hormones including- testosterone, inhibin, estradiol, LH, FSH, prolactin etc (Christensen, 1975; Huang et al, 1991). The testis, which is the major male reproductive organ, is responsible for sperm production or spermatogenesis. Spermatogenesis is the process of transformation of male germ cells into spermatozoa and requires high intratesticular levels of testosterone, produced by the Leydig cells (Ganong, 2001). Furthermore, the synthesis of testosterone is influenced by LH, Prolactin and FSH (Elkington and Blackshaw, 1974).

The marked reduction of testosterone levels by these agents (especially the ACTs) may be as a result of direct deleterious effects on the Leydig cells 
Artesunate, ACTs and their combinants on the hormonal parameters

through generation of oxidative free radicals (Jefford, 2001), with minimal influences on LH, FSH and prolactin. These toxic effects may consequently cause impairment in spermatogenesis. We have therefore carried out a follow-up study to correlate these effects on sperm parameters in the guinea-pig.

The antiplasmodial action of the artemisinins has been attributed to the generation of oxidative stress, because the intraerythrocytic activation of the drug peroxide bond by iron (II)-heme produced during hemoglobin degradation results in the generation of reactive oxygen species- ROS (Jefford, 2001; Robert et al, 2002). Similarly, studies of artemisinins on embryonic stem-cells in mice have shown that these compounds raised intracellular levels of reactive oxygen species (Wartenberg et al, 2003). Furthermore, results of our earlier study (Obianime and Aprioku, 2009) showed that the agents also caused increase in the serum levels of urea which is indicative of oxidative process. Thus, in this study, the inhibition/decrease in serum testosterone level, which is critical for normal spermatogenesis, may be due to oxidative stress on the Leydig cells and other structures in the testis. These oxidative effects were also more pronounced at the lower concentrations of these drugs.

\section{Conclusion}

The artemisinin-based combination treatments (ACTs)-artesunate/amodiaquine and artesunate/ sulfadoxine/pyrimethamine - cause potentiation of the toxicological effects of the artesinin derivative (artesunate) and their combinants (amodiaquine and sulfadoxine/ pyrimethamine) on the male reproductive hormones of the guinea-pig. These effects were observed at the subclinical, normal clinical and double clinical doses of the agents and therefore call for caution in their use. A similar study in humans is currently in progress to evaluate the effects in humans.

\section{Acknowledgement}

We are grateful to Mrs. Matilda Deeko and Mr. Joshua Isirima of the Department of Pharmacology, University of Port Harcourt for their technical assistance. We also thank Mr. Maxwell Azubuike of the Department of Mathematics and Statistics, University of Port Harcourt for his assistance in the statistical analysis.

\section{References}

Adeeko, A.O., and Dada, O.A. (1998). Chloroquine reduces fertilizing capacity of epididymal sperm in rats. Afr. J. Med Sci. 27: 63-64.
Bloland P.B., Ettling M., and Meek S. (2000). Combination therapy for malaria in Africa: hype or hope? Bull World Health Organ. 78: 13781388.

Chawira, A.N., Warhurst, D.C., Robinson, B.L., and Peters, W. (1987). The effect of combinations of qinghaosu (artemisinin) with standard antimalarial drugs in the suppressive treatment of malaria in mice. Trans $R$ Soc Trop Med Hyg. 8: 554-558

Christensen, A.C. (1975). Leydig cells. In: Handbook of Physiology, P.O. Greep and E. B. Astwood (eds.). Washington D.C: American Physiological Society. 165-172.

Curtis, C.F., Otoo, and L.N. (1986). A simple model of the build-up of resistance to mixtures of antimalarial drugs. Trans $R$ Soc Trop Med Hyg . 80: 889-892.

Djimdé, A., Doumbo, O.K., Cortese, J.F., Kayentao, K., Doumbo, S., Diourté, Y., Dicko, A., Su, X.Z., Nomura, T., Fidock, D.A., Wellems, T.E., Plowe, C.V., and Coulibaly, D. (2001). A molecular marker for chloroquine-resistant falciparum malaria. N. Engl J Med. 344(4):299-302.

Elkington, J.S.H., and Blackshaw, A.W. (1974): Studies in testicular function. I. Quantitative effects of FSH, LH, testosterone and dihydrotestosterone on restoration and maintenance of spermatogenesis in the hypophysectomized rat. Aust J Biol Sci.27:47-57.

Ganong W.F. (2001). Review of Medical Physiology. 20th edition. New York: Lange; 239 - 41

Haynes, R.K. (2001). Artemisinin and derivatives: The future for malaria treatment? Curr Opin Infect Dis. 14: 719-726.

Huang, H.F., Pogach, L.M., Nathan, E., Giglio, W., and Seebode, 1. (1991): Synergistic effects of follicle-stimulating hormone and testosterone on the maintenance of spermiogenesis in hypophysectomized rats: relationship with the androgen-binding protein status. Endocrinol. 128:3152-3161.

Jefford, C.W. (2001). Why artemisinin and certain synthetic peroxides are potent antimalarials: Implications for the mode of action. Curr Med Chem. 8: 1803-1826.

Kofi, Ekue J.M., Ulrich, A., and Njelesani, E.K. (1983). Plasmodium malaria resistant to chloroquine in a Zambian living in Zambia. $\mathrm{Br}$ Med J. 286:1315-1316.

McIntosh, H.M., and Olliaro, P. (2000). Artemisinin derivatives for treating uncomplicated malaria. Cochrane Database Syst Rev. 2: 256.

Mulenga, M. (1998). Facing drug resistance: therapeutic option for treatment of uncomplicated 
A. W. OBIANIME and J. S. APRIOKU

Plasmodium falciparum malaria in adult Zambians. J. Med. Health Sci. 2(1): 11-20.

Nosten, F., and White, N. J. (2007). ArtemisininBased Combination Treatment of Falciparum Malaria. Am. J. Trop. Med. Hyg. 77(6): 181-192.

Nwanjo, H.U., Iroagba, I.I., Nnatuanya, I.N., and Eze, N.A. (2007). Antifertility Activity Of Dihydroartemisinin In Male Albino Rats. The Internet J. Endocrinol. 4(1).

Obianime, A.W., and Aprioku, J.S. (2009). Comparative study of artesunate, ACTs and their combinants on the biochemical parameters of the male guinea-pig. Afri J. Biotech. 8(19): 50595065.

Orisakwe, O.E., Obi, E., and Udemezue, O.O. (2003). Effect of halofantrin on testicular architecture and testosterone level in guinea pigs. Eur. Bull. Drug Res. 11: 105-109

Price, R.N., Van, Vugt M., Nosten, F., Luxemburger, C., Brockman, A., Phaipun, L., Chongsuphajaisiddhi, T., and White, N.J. (1998). Artesunate versus artemether for the treatment of recrudescent multidrug-resistant falciparum malaria. Am J Trop Med Hyg. 59: 883-888

Raji, Y., Osonuga, T.O., Akinsomisoye, O.S., Osonuga, O.A., and Mewoyeka O.O. (2005). Gonadotoxicity evaluation of oral artemisinin derivatives in male rats. J. Med. Sci. 5(4): 303306.

Robert, A., Dechy-Cabaret, O., Cazelles, J., and Meunier, B. (2002). From mechanistic studies on artemisinin derivatives to new modular antimalarial drugs. Acc Chem Res. 35: 167-174.

Sachs, J., and Malaney, P. (2002). The economic and social burden of malaria. Nature. 415: 680 -685.

Sairam, M.R. (1978). Drug effects on lutropin action. In: K.W McKerns (Ed). Structure and
Function of Gonadotrophins. New York: Plenum, 274-294.

Wartenberg, M., Wolf, S., Budde, P., Grünheck, F., Acker, H., Hescheler, J., Wartenberg, G., and Sauer, H (2003). The antimalarial agent artemisinin exerts antiangiogenic effects in mouse embryonic stem cell-derived embryoid bodies. Lab Invest. 83:1647-1655.

Wellems, T.E., and Plowe, C.V. (2001). Chloroquine-resistant malaria. J. Infect. Dis. 184: 770-776.

White, N.J. (1999). Antimalarial drug resistance and combination chemotherapy. Philos Trans $R$ Soc Lond B Biol Sci. 354: 739-749.

White, N.J., Nosten F., Looareesuwan, S., Watkins, W.M., Marsh, K., Snow, R.W., Kokwaro, G., Ouma, J., Hien, T.T., Molyneux, M.E., Taylor, T.E., Newbold, C.I., Ruebush, T.K., Danis, M., Greenwood, B.M., Anderson, R.M, and Olliaro, P. (1999). Averting a malaria disaster. Lancet. 353:1965-1967.

World Health Organization (1994/95). The role of artemisinin and its derivatives in the current treatment of malaria. Geneva.

World Health Organization. Malaria Chemotherapy (1998). Tech. Reg. Ser. Geneva.

Yeung, S., Pongtavornpinyo, W., Hastings, I.M., Mills, A.J., and White, N.J. (2004). Antimalarial Drug Resistance, Artemisinin-Based Combination Therapy, and the Contribution Of Modeling To Elucidating Policy Choices. Am. J. Trop. Med. Hyg. 71(2): 179-186.

Received: August 15, 2009

Accepted: December 17, 2009 